\title{
Entre as duas vezes que o corpo dançou: Coreografia para a câmara Bausch, Fuller e Deren
}

ANA RITO 


\section{- RESUMO}

É a imagem videográfica que, registando o corpo, edifica o conceito de "coreografia para a câmara", não pressupondo que as acções sejam experienciadas ao vivo por um público, logo permitindo um desfasamento conceptual que auxilia a definição de um campo esquivo e entre mundos: os gestos são agora "arquivos" do corpo em trânsito.

A figura, agora tornada o corpo da imagem (podemos talvez considerar dois corpos unidos, o corpo enquanto figura, e o corpo próprio do vídeo ou do filme enquanto representação, "objecto"), estabelece a transmutação e a instabilidade da própria condição do medium das imagens em movimento - filme ou vídeo.

\section{PALAVRAS-CHAVE}

Corpo performativo, imagem movente, presença, ausência, coreografia

\section{ABSTRACT}

It is the video image that, registering the body, builds the concept of "choreography for the camera," not assuming that the actions are experienced live by a public, allowing a conceptual gap that assists the definition of an elusive field and between worlds : gestures are now "archives" of the body in transit.

The figure, now made the body-image (perhaps we can consider two joined bodies, the body as figure, and the body's own video or film as representation, "object"), establishes the transmutation and the instability of the moving images medium - film or video.

\section{KEYWORDS}

Performative body, moving image, presence, absence, choreography

\section{Introdução}

A dança e o vídeo têm afinidades particulares e, a partir das suas experiências e destas afinidades, surge a vídeo-dança, onde o corpo dançante cruza as proposições videográficas depois de ter constituído a fatalidade coreográfica da invenção cinematográfica. ${ }^{1}$ (Parfait, 2001, 203.)

Douglas Rosenberg em Screendance: Inscribing the Ephemeral Image (2012) reflecte em torno das relações entre a prática da dança e as novas tecnologias de representação desde o advento do cinema, apresentando uma espécie de mapa de navegação e questionando os limites de uma forma de arte profundamente colaborativa.

A efemeridade do movimento do corpo e a imagem que daí decorre aponta para uma abordagem interdisciplinar que permite uma discussão mais ampla das questões de hibridismo e mediação. A genealogia da "coreografia para a câmara", que difere, na sua natureza e parâmetros definidores, do registo audiovisual ou fotográfico de um exercício ou espectáculo de dança, coloca um conjunto de questões que importa enformar. $\mathrm{O}$ que sucede aos corpos coreografados, agora virtuais, no processo de re-mediação, que esta transferência, este "corpo tornado imagem"

$\overline{1}$ PARFAIT, Françoise, Video: Un Art Contemporain, Paris: Éditions du Regard, 2001, p.203. 
desenha? Podemos ainda falar de fisicidade/materialidade associada à tecnologia que permite esta re-mediação?

Por sua vez, Susan Leigh Foster, em Choreographing Empathy: Kinesthesia in Performance (2011) coloca a tónica no espectador, cujo corpo físico dialoga com o corpo virtual da imagem, propondo a existência de uma conexão sensorial, iminentemente cinestésica e empática no decorrer do processo de re-mediação. A partir do corpo performativo, nas suas re-lações com o espaço, e do corpo registado, encapsulado no medium da imagem cinemática e videográfica, registando a performance do corpo, avançamos para a tentativa de uma definição que conjugue estes momentos. O mesmo pressuposto é convocado, de outro modo, em Dancefilm: Choreography and the Moving Image, onde Erin Brannigan (2011) propõe uma "terminologia interdisciplinar" e aponta um modelo para a discussão de significados e derivações. Os elementos formais que compõem uma performance ou coreografia para a câmara, tais como o close-up, o loop, o frame, o hors-champ, a edição/colagem ou o som, articulados à intertextualidade, à a-narratividade e ao carácter abstracto de algumas soluções compósitas esboçam uma possível constelação operativa (observe-se ainda a edição como um processo coreográfico, na medida em que esta permite moldar o fluxo, a sequência dos gestos através da manipulação da imagem, do corte ou do enquadramento, construindo o ritmo e a cadência dos movimentos: a chamada "frase coreográfica" compreende uma série de acções e pontos de ênfase agrupados, associando fracções de filme para criar uma noção de passagem do tempo).

A imagem cinematográfica ou videográfica manifesta a ausência de uma presença, projectando, pelas suas especificidades e possibilidades técnicas, uma noção de hibridez que importa observar e explorar.

Segundo as premissas e as referências desenhadas neste apontamento introdutório, a nossa análise centrar-se-á em casos específicos: Loie Fuller, Maya Deren e Pina Bausch são anotadas como uma espécie de "figuras-léxico" que determinam uma nomenclatura, e uma especificidade, essencial ao nível dos vários discursos. A "verticalidade poética" de Deren, "a imaterialidade do corpo" de Fuller e o "corpo colectivo" de Bausch são disso exemplo.

\section{Como se as palavras gesticulassem para dentro: Pina de Wim Wenders}

Em 2011 Wim Wenders realiza o filme Pina (a film for Pina Bausch), num formato próximo do documentário, onde apresenta os bailarinos da companhia-casa fundada pela coreografa alemã (homenagem póstuma). A corrente expressionista alemã formou um importante número de figuras como o coreógrafo Rudolf von Laban (introdutor do ensino e da prática do movimento, da dança sem música) ou as bailarinas Mary Wigman (cuja Totentanz/Dança da Morte de 1926 se tornou emblemática deste período), Gret Palucca e ainda Kurt Jooss, introdutor da ideia de dança-teatro e mestre de Pina Bausch. No seguimento desta experiência surge o Wuppertal Tanztheater (1973), onde Bausch desenvolveu uma coreografia dominada por questões existenciais, onde os corpos são empurrados para a beira da exaustão, muitas vezes através de cenários marcantes, como um incalculável conjunto de cadeiras, um palco imerso por uma chuva de flores, ou ocupado por aglo- 
merados de tijolos. Influenciada pela abordagem filosófica de Jooss, Pina incorporou diferentes linguagens artísticas, reminiscentes da dança clássica, da dança moderna e do teatro, na procura de uma "fala" própria. Outro dos legados pedagógicos do seu professor seria a participação activa dos bailarinos na criação das coreografias. As suas personalidades, as suas narrativas pessoais e as suas vivências, estão presentes no processo compósito dos gestos e dos movimentos. As fragilidades e as inquietações de cada corpo são exploradas na tentativa de humanização do palco, da "cena", e de aproximação ao sujeito/espectador. O filme é composto por extractos de algumas das peças mais dançadas de Bausch: Le sacre du printemps (Frühlingsopfer), Café Müller, Kontakthof e Vollmond, imagens de arquivo e reinterpretações, performances para a câmara (alguns solos e duetos), acompanhadas por entrevistas e cenas nas imediações do Teatro e nas carruagens do Wuppertal Schwebebahn. Dos quatro momentos salientamos dois: Café Müller, exibe um cenário simples que consiste num conjunto de mesas, cadeiras e portas, onde três mulheres (uma das quais aparenta ser cega) lutam para se desviar destes objectos que obstruem a sua marcha. Dois homens surgem em cena na tentativa de "desentulhar" o espaço, possibilitando a passagem das mulheres. Os cinco iniciam assim uma dança-embate que se repete até à queda dos corpos (e em loop); Kontakthof (lugar de encontro) é apresentado primeiramente na Wuppertal Tanztheater em 1978. Os bailarinos, em trajes formais, são divididos em dois grupos distintos. Homens e mulheres realizam acções quotidianas separadamente, como escovar os dentes, esfregar as mãos, coçar a orelha, segurar os cabelos ou acenar, que assumem a forma de ritual quando executados em simultâneo. A peça reflecte sobre a interacção humana, interrogando os tabus corporais e as construções sociais, como a identidade e o género. Neste palco-pátio e numa espécie de dança-jogo são observados ritos de acasalamento, exercícios de sedução e poder que caracterizam a voz de Bausch, "audível" a cada movimento, a cada passo. Uma segunda versão, com intérpretes não profissionais maiores de 65 anos, estreou em 2000, seguida de uma terceira "tradução" com jovens adolescentes entre os 14 e os 17 anos em 2008. A observância de corpos distintos permitiu a diversidade dos gestos, dos tempos e dos ritmos. O mesmo movimento terá agora abordagens diferentes, irrepetíveis e intransferíveis, possibilitando a criação de uma poética singular e característica de uma abordagem liberta e inovadora à composição coreográfica e consequentemente à dança contemporânea. Para uns, as memórias do corpo dominam as acções, para outros, o entusiasmo possibilita a frescura da marcha. A gravidade, a lentidão, a profundidade e a prudência de uma comunidade contrastam com a leveza, a insegurança, o fascínio e a impaciência da outra. As três versões, as três comunidades complementam-se: a técnica, a tenacidade e a jovialidade constituem um só corpo: um corpo que espelha um rosto, o rosto de Pina (Wenders editou as três versões dando continuidade à coreografia).

Por seu lado, Pina (o filme) introduz uma relação inédita com o espectador, mergulhando-o, através de imagens estereoscópicas ${ }^{2}$, numa configuração espáciotemporal específica: a partilha do palco com os bailarinos. Central neste processo parece ser a tensão entre os diferentes planos/pontos de vista: aproximações e

\footnotetext{
${ }^{2}$ Sobre o assunto ver Lenny Lipton, Foundations of the Stereoscopic Cinema. New York: Van Nostrand Reinhold, 1982 .
} 
afastamentos que permitem uma percepção ritmada do corpo movente do intérprete ausente e a própria fisicidade do sujeito/observador presente. Esta suspensão momentânea entre estados, entre presença e ausência, possibilita uma leitura hibridizada do projecto de Wenders (e Pina).

Para Thomas Elsaesser (2010) a tecnologia 3D não é apenas um efeito especial mas antes um outro nível de percepção visual (extensível a outros sentidos), herdeiro do "cinema de atracções" de espectáculo e performance como descreve Elizabeth Coffman $(2002,79)$.

O fascínio (contemporâneo) pelo excesso (ou excessivo) é satisfeito pela capacidade das imagens estereoscópicas em gerar efeitos pop-out, que, combinados com um corpo dançante, propiciam um novo entendimento da imagem movente. Alain Derobe, técnico especializado em estereoscopia convidado por Wenders a produzir o filme, fala da dificuldade em filmar corpos dançantes com a tecnologia 3D: as câmaras são colocadas em cena, junto aos bailarinos, "dançando" conjuntamente com estes, relacionando-se fisicamente com os seus gestos, os seus movimentos e as suas pausas. O filme retrata a experiência do movimento em detrimento da narrativa. A dança e o cinema (como já vimos anteriormente) têm uma história conjunta que combina uma tecnologia a um desígnio do corpo (exemplos que vão desde as experiências proto-cinemáticas de Eadweard Muybridge, ao phonoscope de Georges Demenÿ, às copy-cat de Loïe Fuller e as suas relações com os irmãos Lumiére e Edison - como desenvolveremos de seguida - ou ao slow-motion de Lydia Lopokova). Na sua génese, a dança, os seus corpos em movimento e as suas imagens, retêm uma a-narratividade própria ${ }^{4}$, afastando-se (ao longo da sua trajectória) do cinema mainstream (clássico ou narrativo), aproximando-se por sua vez do cinema experimental, e surgindo depois no âmago dos musicais hollywoodescos, ao adoptar uma forma mais descritiva e ilustrativa.

Em Pina, a tecnologia 3D situa o corpo dançante do performer junto do espectador, originando uma acentuada sinergia entre ambos que forma, por sua vez, o fluxo/palco comum de que fala Patrice Pavis (2003). Deste modo, e como resultado do efeito estereoscópico, a distância entre o bailarino e a audiência é reduzida, na medida em que este procedimento constrói ecrãs/planos intermédios, onde é destacado, por exemplo, um corpo em relação ao restante grupo, na intenção de penetrar a zona da plateia (veja-se uma das últimas cenas em que o palco está inundado e a cada movimento mais enérgico dos bailarinos, a água salpica os seus corpos e parece atingir também o espectador - situando-se precisamente nesse ecrã/plano intermédio).

A profundidade criada por estes planos (que se sucedem) e os movimentos da própria câmara ampliam a sensação de se estar "em cena" junto aos corpos moventes, de se ter chão, para com eles dançar. Existe também aqui um sentido voyeurístico, no sentido em que, através da tecnologia, é-nos permitido, enquanto observadores, profundar no seio de uma comunidade (muitas vezes silenciosa) de entidades absortas nas suas actividades e cuja intimidade parece estar a ser violada ou espiada, como já nos indicava Kracauer $(1997,44)$.

\footnotetext{
$\overline{3}$ Ver Tom Gunning, "The Cinema of Attractions: Early Film, Its Spectator and the Avant-Garde", Thomas Elsaesser (ed.) Early Cinema: Space-frame-narrative (London: BFI Publishing, 1990), pp.57-62. Ver também William Paul, The Aesthetics of Emergence, Film History, 5:3 (1993), pp.321-355.

${ }^{4}$ Característica que aproxima a dança, e as suas imagens, do espetador como propõe Patrice Pavis em Analysing Performance. Ann Arbor, University of Michigan Press, 2003, p.128. 
Estas duas perspectivas simultâneas - um novo "realismo voyeurista" que tem a capacidade de se aproximar impunemente do objecto/sujeito de desejo sem ser visível ou denunciado e a pertença consciente ao espaço virtual do ecrã - sublinham a posição paradoxal do espectador e a potencialidade do uso da câmara na exploração e estudo do movimento. Numa cena de Pina, onde se encontram em cena várias bailarinas, é oferecido um pedaço de tecido vermelho (um vestido) à própria câmara, que substitui assim um dos performers originais. O close-up dirigido aos seus rostos de contornos arredondados (as superfícies esféricas salientam o efeito de tridimensionalidade produzido pela visão estereoscópica) é acentuado pela "hiper-realidade" possibilitada pelo 3D, resultando em imagens de grande plasticidade, reveladoras de toda a textura e especificidade da pele suada de cada um dos intérpretes. Esta capacidade de "atracção", já comentada por Balász, Deleuze, Epstein ou Gunning, reportando-se em uníssono ao plano (muito) aproximado, atravessa todas as imagens de Wenders e todos os corpos de Pina, na constituição da sua "zona de contacto".

\section{O corpo proto-cinemático de Loie Fuller e as imagens coreografadas de Maya Deren}

A passagem do séc. XIX para o séc. XX anuncia um novo entendimento do corpo, mais especificamente do corpo em movimento, que encontra nas relações da dança com o cinema o seu mais pertinente manifesto, como refere Gilles Deleuze em Cinémal: L'Image-Mouvement (1983), quando aplica as teorias de Henri Bergson (1990) numa equação que relaciona a dança moderna e o advento cinematográfico na construção de uma nova filosofia do "movente". A dança pretendia isentar-se de qualquer índole classicista, abdicando de figuras e poses canónicas determinadas, perscrutando a condição a-descritiva do gesto. Em 1892, Loïe Fuller (bailarina norte-americana residente em paris) inaugura um novo género de dança recorrendo a um figurino concebido por si, que consistia num longo vestido plissado branco, manipulado através de duas longas varas que "estendiam" os seus braços, iludindo e hipnotizando o espectador: a chamada Danse Serpentine. Fuller apossa-se de forma inédita das potencialidades estéticas associadas às novas tecnologias, sendo descrita por Sally Sommer, no seu ensaio de 1975, intitulado Loïe Fuller, como uma espécie de "imagem em movimento", re-configurando o "corpo que se move", a partir de três paradigmas: as suas coreografias apontam um carácter proto-cinemático, que interessa aqui reter, na criação de jogos hipnóticos de luz e de sombra, de artifícios cromáticos poderosos e dinâmicos que edificam uma espécie de corpo abstracto, indefinido, volátil e inconstante na sua mobilidade, a mesma que anima as projecções que ocorrem sobre a sua superfície; do domínio tecnológico à representação sequencial do movimento, as coreografias de Fuller instituem um corpo-ensaio; os movimentos e a indumentária exuberante, um tecidopele fluído, de seda, manipulado com destreza e que utiliza em palco, permite o "espaçamento" de um corpo que se desenvolve em cena, que dialoga de forma imponderável com a carne e o espectro, com a presença e a ausência - um corpo que estabelece o próprio dispositivo de aparição da imagem, ou seja um corpo-ecrã. 
La Serpentine (cuja primeira apresentação data de 1892), La Violette, Le Papillon e La Danse Blanche expressam uma "nova cinestesia", num movimento fluído que nasce no centro do corpo, repleto de transições e posições que progridem para uma maior complexidade ao longo das várias exibições. O corpo múltiplo e "informe" resultante destas metamorfoses parece flutuar e levitar no palco, acentuando a efemeridade do gesto e da pose - a dança ocorre nos interstícios, de uma ação para outra, de um passo para outro, e de uma posição para outra, não surgindo a figura num único momento mas na continuidade do movimento.

A Danse Serpentine, captada pela objetiva dos Lumiére em 1897-1899, (a intérprete é comummente identificada como sendo Fuller, no entanto, alguns estudos apontam para uma copy-cat ${ }^{5}$, algo muito em voga na época, sendo Annabele Moore uma das suas imitadoras mais famosas, surgindo em algumas filmagens de Mélies e Alice Guy), corporifica de forma inédita a relação entre o movimento e a imagem, realizando uma performance para a câmara.

A dança, em plena fase de mutação, tenta participar das correntes revolucionárias da modernidade no momento em que a prática literária simbolista, os estudos contemporâneos sobre a locomoção e as teorias filosóficas relacionadas com o movimento de Bergson, protagonizavam o contexto cultural na Europa. Declinando qualquer carácter decorativo, ilustrativo, superficial e classicista, a dança accionou uma inquietante transdisciplinaridade e Fuller parecia representar esta convulsão, centrando no corpo as preocupações vigentes.

Em They Film as They Dance (1991), Annie Bozzini6 aponta Fuller como a primeira bailarina e coreógrafa a realizar um filme experimental, Le Lys de la Vie, de 1920 com Gabrielle Bloch. Terá deixado outros dois projectos cinematográficos inacabados, Vision des Rêves, de 1924, e Les Incertitudes de Coppelius, de 1927. É instaurada uma nova consciência do corpo, das suas coordenadas e possibilidades motoras: uma cinestesia reiterada através do fluxo constante, de que nos fala Bergson. Nesta perspectiva, Fuller coloca-se entre o palco e o ecrã, no cerne das transformações do corpo-performativo, assim como na construção do corpo-cinemático, antecipando a linguagem de Maya Deren na medida em que ambas reflectem sobre a construção da imagem do corpo-coreográfico (ou coreografado): desenvolvendo dispositivos visuais que enunciam o seu programa estético, através dos mecanismos de projecção de luzes, sombras e cor em reciprocidade com a sua tradução performativa em palco, Fuller conduz o espectador a uma experiência cinematográfica singular. Por seu lado, e na configuração dos seus "filmes-ensaios" avant-garde, Deren explora um conjunto de efeitos visuais, como a múltipla exposição, o corte, ou o slow-motion. Por volta de 1939, Deren torna-se secretária pessoal da coreógrafa e antropóloga Katherine Dunham. No documentário, In the Mirror of Maya Deren (2001), de Douglas Wolfsberger, Dunham refere algumas performances de Maya ao som de tambores, aquando de certos eventos da sua Companhia, existindo mesmo uma menção à vontade de Deren em integrar a Companhia como bailarina. Aliás Deren, assim como Fuller, é protagonista e performer de alguns dos seus próprios filmes e vem a cooperar com membros da Companhia de Dunham, como os dançarinos Talley Beatty e Rita Christiani. A dança está notoriamente presente em

\footnotetext{
${ }^{5}$ Sobre o assunto ver: LISTA, Giovanni, Loïe Fuller et ses imitatrices, Cinémathèque de la danse in Paris, 1994.

${ }^{6}$ Annie Bozzini citada por Martha BREMSER - Fifty Contemporary Coreographers. London and New York: Routledge, 2000.
} 


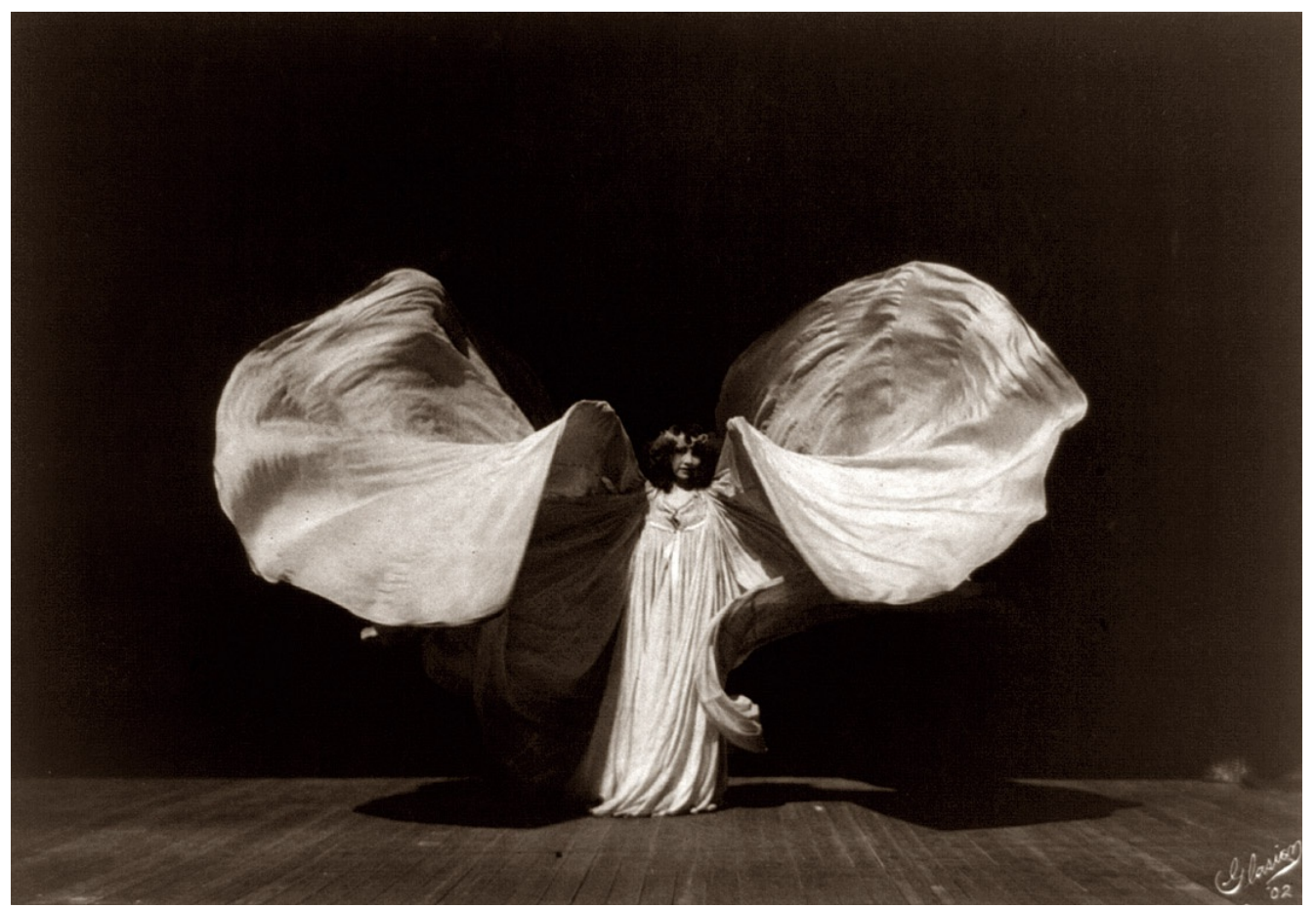

Figura 1. Loïe Fuller fotografada por Frederick Glasier, 1902.

cinco dos seus filmes: A Study in Choreography for Camera (1945), Ritual in Transfigured Time (1945-46), Meditation on Violence (1948), The Very Eye of Night (1952-55, exibido em 1959) e Divine Horsemen (obra póstuma realizada entre 1947 e 1954). Deren manifesta uma sensibilidade coreográfica (embora nunca se tenha denominado de coreógrafa, assume créditos autorais com Talley Beatty em A Study in Choreography for Camera, de 1945 e com Frank Westbrook para Ritual in Transfigured Time, de 1945-46) no que respeita ao corpo-performativo e à produção cinematográfica, "enquadrando" o gesto que designa o movimento7. O silêncio das performances de At Land (1944), A Study in Choreography for Camera (1945), e de Ritual in Transfigured Time (1945-46) afasta-a de uma genealogia fílmica que se detém numa óptica literal da acção, ao invés, Deren compõe situações que perscrutam o gesto nas suas possibilidades expressivas e linguístico - semânticas em detrimento da palavra. O enquadramento que "fracciona" o corpo, como com Chao-li Chi, em Meditation on Violence, expõe a carne que se mostra nas suas cavidades, nos seus esconsos, e que se assume como um "horizonte de acontecimentos", um palco onde o acto acontece, onde a coreografia nasce. No contexto de um Simpósio sobre Poesia e Filme ${ }^{8}$, em 1953, Deren define aquilo que considera ser a sua forma cine-

\footnotetext{
7 "Para criar uma nova forma, os elementos devem ser seleccionados de acordo com a sua capacidade para funcionar no novo, "anti-natural", contexto. Um gesto que poderia ter sido bastante eficaz no decorrer de uma conversa espontânea e natural, poderá falhar em ter impacto na dança ou no filme". Maya Deren citada por Bill NICHOLS, Maya Deren and the American Avant-Garde, California: University of California Press, 2001, p. 23. Tradução livre da autora.

8 O Simpósio foi organizado para o Cinema 16, Cinema Society, por Amos Vogel. Os textos das comunicações do Simpósio foram publicados em Jonas Mekas' Film Culture, The Film Culture Reader, editado por P. Adams Sitney, Prager Publishers Inc., New York, 1970, pp.171-86.
} 
matográfica e a sua linguagem cinematográfica, na rejeição daquilo que designa de "estrutura horizontal" (que relaciona com um processamento interno que promove a narrativa linear, a caracterização, a catalogação de personagens e lugares), defende uma estrutura poética ou "vertical", aquela que não subjuga o filme à linearidade composicional e interpretativa. Esta ideia aproxima-a a Gilles Deleuze (2000) quando este distingue "imagem-movimento" de "imagem-tempo": o seu modelo de "imagem-movimento" traça o encadeamento linear de uma estrutura fílmica que se alicerça na "acção-reacção", ao passo que a "imagem-tempo" resulta de situações puramente visuais, motoras e sonoras ${ }^{9}$. Deren estabelece assim dois eixos: o eixo horizontal que compreende elementos narrativos e descritivos, e o eixo vertical, caracterizado por exercícios em torno do ritmo, do tom, da óptica e do enquadramento do gesto, assumindo uma desconstrução que se centra no corpo e nas suas ações, nas suas capacidades físicas, expressivas e semióticas. Em A Study in Choreography for Camera (1945) a coreografia de Talley Beatty e o processo de edição de Deren colocam em cena esta "verticalidade", compondo um jogo continuado entre a estabilidade e a instabilidade, onde um corpo sem chão ombreia com a inevitabilidade da gravidade e do seu próprio peso, num maneio de opostos que diferencia a prática da dança. O palco, por convenção, é o lugar onde o bailarino executa a sua coreografia, apresentada para um público que, por norma, se encontra de frente para este. Pelo contrário, e neste caso, uma coreografia registada pela objectiva de uma câmara procura libertar o corpo do bailarino de qualquer constrangimento físico, procura retirá-lo do palco estático, alterando o cenário constantemente e considerando novas relações entre o corpo e o espaço, o corpo e o tempo. A exploração de determinadas práticas cinematográficas, convertem o espaço num participante activo na coreografia, motor de dinamismo, e provido de capacidades discursivas. Deren introduz um dueto, um pas de deux entre o espaço e o corpo do bailarino, do qual a câmara não é apenas um observador, um "olho sensitivo", mas é, antes, responsável pela performance de um ponto de vista criativo. A continuidade da coreografia questiona a descontinuidade espacial. Esta sequência promove uma poética do movimento, a-funcional, a-narrativo, a-linear. A fluidez do jogo em torno do centro gravitacional cria uma "janela" dentro do filme que conduz à contemplação do "puro movimento". Veja-se Paul Valéry (1964), quando discorre sobre a dança e o poema contínuo do corpo, advogando que a fórmula para alcançar a pureza dos movimentos não devia incluir nada que sugerisse o seu fim. A objectiva converte-se em performer, a par de Beatty, na medida em que a sua "actuação" é determinante para o concretizar de uma visão inovadora, numa sincronização entre o movimento da câmara e o movimento do corpo ${ }^{10}$. A Study in Choreography for Camera expressa a libertação do corpo em movimento do bailari-

\footnotetext{
$\overline{9}$ "Se a imagem-movimento é assimilada na cena, chamamos enquadramento ao primeiro momento da cena com vista aos objetos e à montagem o outro momento que se dirige ao todo (...) é a montagem ela própria que constitui o todo e, logo, que nos fornece uma imagem do tempo. É, pois, o principal ato do cinema. O tempo é necessariamente uma representação indireta porque flui da montagem, que interrelaciona uma imagem-movimento a outra. É devido a isto que a relação não pode ser simples justaposição: o todo não é mais do que uma sucessão de presentes (...) A montagem deve proceder de alterações, conflitos, resoluções e ressonâncias, em suma, uma atividade de seleção e coordenação, de forma a atribuir ao tempo a dus dimensão real, e ao todo a sua consistência." DELEUZE, Gilles - Cinema2- The Time-Image. London: The Athlone Press, 2000, p.34-35. Tradução livre da autora.

10 Em 1943, Deren colaborou com Marcel Duchamp na criação de um filme intitulado Witch's Cradle, onde experienciou pela primeira vez esta relação entre a câmara e o performer (neste caso, o próprio Duchamp).
} 
no dos limites físicos do palco, que se estabelece no ritmo gerado pela alternância entre o acentuado slow - motion e a extrema aceleração, fixando o gesto ou experienciando a duração da ação. Como refere no seu ensaio An Anagram of Ideas on Art, Form and Film: "O slow-motion é o microscópio do tempo" $(2000,46)$.

Em The Very Eye of Night (1958), Maya Deren colabora com o Metropolitan Opera Ballet School, desenvolvendo uma enigmática "dança da noite". A imagem surge em negativo, criando um espaço nocturno, animado por um intenso som hipnótico.

A escuridão da noite desvanece a linha do horizonte, libertando os movimentos, dos bailarinos e da câmara, da estaticidade e da horizontalidade, aproximando a coreografia dos corpos à ideia de voo ou de mergulho.

Deren apossa-se de gestos estilizados, e é na repetição destes gestos que cria um circuito de expressões que atua fora de qualquer sistema de classificação. É através do filtro cinematográfico que estes gestos geram novas significações. Observamos um processo de (des)velamento - (des)velar um corpo que une em si o claro e o escuro, que se movimenta numa zona de luz e de sombra em simultâneo "cravando o olho" no intervalo, no espaçamento entre um e o outro, entre os corpos que dançam, que se tocam, que se escondem, que se vêm.

Um raio de luz ressoa os limites de um corpo que se dispõe no limiar do seu (des) aparecimento. A luz deseja o corpo que se dissimula na sombra.

Resta-nos suster a respiração.

\section{Apontamento Final}

O corpo movente (e coreografado) é redesenhado constante e profundamente, através das imagens que a partir dele são criadas e que de alguma forma, devolvem o reflexo, transformando-o a cada olhar. Este corpo atravessa conceitos, experiencia a teatralidade, a encenação, a coreografia, o gesto, o movimento e coloca-se em rota de colisão com qualquer tentativa de codificação mais clássica.

O paradoxo da imagem movente (e coreografada) opera no sentido em que esta direciona a atenção do espetador para um momento específico no tempo - em direcção ao real e construído por si - mas através de mecanismos ilusórios ou imersivos. No ensaio In a Moment: Film and the Philosophy of Modernity, Leo Charney (1995) descreve este instante "corpo a corpo" como "um momento sensual de presença" manifesto em forma de encontro. Este "momento da visão" (Heidegger, 1996) provém da interseção (intuitiva) entre a ilusão e a realidade, o real e o virtual, resultando numa "sensação momentânea de presença".

Assim, e fazendo da "coreografia para a câmara" matéria (e experiência) primordial de reflexão, o presente texto pretendeu estabelecer a sua génese operativa a partir da observação dos momentos de transição, de contacto, de suspensão, de cruzamento e de hesitação entre o corpo e a imagem. 


\section{Referências}

BERGSON, Henri, Matéria e Memória: Ensaio sobre a relação do corpo com o espírito. São Paulo: Martins Fontes, 1990.

BREMSER, Martha, Fifty Contemporary Coreographers. London and New York: Routledge, 2000.

BRANNIGAN, Erin, Dancefilm: Choreography and the Moving Image. New York: Oxford University Press, 2011.

CHARNEY, Leo, SCHWARTZ, Vanessa. 1995. In a Moment: Film and the Philosophy of Modernity in Cinema and the Intervention of Modern Life. Berkeley: UCP.

COFFMAN, Elizabeth, Women in Motion: Loie Fuller and the 'Interpenetration' of Art and Science in Camera Obscura, 17:1, 2002.

DELEUZE, Gilles, Cinéma1: L’Image-Mouvement. Paris: Les Éditions de Minuit, 1983.

DELEUZE, Gilles, Cinema2- The Time-Image. London: The Athlone Press, 2000.

DEREN, Maya - An Anagram of Ideas on Art, Form and Film. New York: The Alicat Book Shop Press, 2000.

ELSAESSER, Thomas, The Dimension of depth and objects rushing towards us in, eDIT Filmmaker's Magazin (2010) (http://www.edit-frankfurt.de/en/magazine/ausgabe-12010/the-dimension-of-depth/the-dimesion-of-depth-and-objects-rushing-towards-us.html)

FOSTER, Susan Leigh, Choreographing Empathy: Kinesthesia in Performance. New York: Routledge, 2011.

HEIDEGGER, Martin Heidegger. Being and Time. New York, Albany: State University New York Press, 1996.

KRACAUER, Siegfried, Theory of films: the redemption of physical reality. Princeton: Princeton University Press, 1997.

NICHOLS, Bill, Maya Deren and the American Avant-Garde. California: University of California Press, 2001.

PAVIS, Patrice, Analysing Performance. Ann Arbor, University of Michigan Press, 2003.

ROSENBERG, Douglas, Screendance: Inscribing the Ephemeral Image. New York: Oxford University Press, 2012.

SOMMER, Sally, Loïe Fuller, The Drama Review, v.19, n.1, March 1975. 
VALÉRY, Paul, The Philosophy of Dance, in Aesthetics (v.13 of Collected Works). New York: Pantheon Books, 1964. 